\title{
A INEFETIVIDADE CONSTITUCIONAL É UM PROBLEMA DE (IN) JUSTIÇA?
}

Flávio Pierobon ${ }^{1}$

PIEROBON, F. A inefetividade constitucional é um problema de (in) justiça? Rev. Ciênc. Juríd. Soc. UNIPAR. Umuarama. v. 17, n. 2, p. 243-259, jul./dez. 2014

RESUMO: A constituição brasileira é caracterizada pelos diversos direitos fundamentais que resguarda. Esses direitos são dotados, em teses, de um mínimo de eficácia social e jurídica, bem como de aplicabilidade imediata. Entretanto, muitos desses direitos fundamentais não geram qualquer efeito na vida das pessoas. A falta de efetividade, em muitos casos, está ligada à (não) atuação dos órgãos do Estado. A questão, por vezes, termina no Judiciário. Pode o Judiciário, com base diretamente na Constituição Federal fazer as escolhas que cabem aos outros Poderes? Se não fizer, atende a Constituição, que exige aplicabilidade imediata aos Direitos fundamentais? Além disso, com base no conceito de justiça de John Rawls, é possível dizer que a inefetividade dos direitos fundamentais é vetor de injustiça? O ensaio que se propõe visa a discutir tais questões sob a luz de uma Constituição normativa em um Estado democrático de Direito que está influenciado pelas ondas de judicialização dos conflitos.

PALAVRAS-CHAVE: Direitos Fundamentais; Justiça; Substancialismo; Procedimentalismo.

\section{INTRODUÇÃO}

A questão que se coloca em debate está relacionada à ideia de efetividade constitucional, mais propriamente à efetividade das normas constitucionais definidoras de direitos fundamentais. A discussão não deve ser pautada apenas em uma teoria geral do direito constitucional, mas voltada precipuamente para a realidade brasileira. Assim, a ideia de efetividade das normas constitucionais, em especial aquelas ligadas aos direitos sociais, será abordada por meio do debate dos mecanismos de efetivação de tais normas que estão disponíveis no direito brasileiro.

O problema se coloca exatamente na forma de se efetivar as normas constitucionais, em especial as normas que estabelecem direitos sociais, partindo de uma concepção democrática do direito.

${ }^{1}$ Mestrando em Ciência Jurídica pela UENP. Professor de Direito Constitucional. Advogado. 
Assim, a questão esbarra na teoria da separação de poderes, em especial em relação a saber qual dos poderes deverá dar às normas constitucionais a eficácia que a própria constituição reclama $\left(\operatorname{art.} 5^{\circ}, \S 1^{\circ}\right)$.

É possível verificar na atual Constituição brasileira dispositivos que não apresentam real efetividade. Dentre tais dispositivos se pode citar, como exemplo aleatório, o art. $7^{\circ}$, IV da CF/88, que trata do salário mínimo.

Diante disso, pode-se dizer que os mecanismos estabelecidos para a efetivação dos dispositivos constitucionais têm apresentado algum déficit, recaindo sobre o Judiciário questões que inicialmente deveriam ter sido resolvidos no âmbito administrativo ou legislativo.

O Judiciário ao se deparar com tais causas tem como ferramentas o direito posto e, por meio de interpretações que faz dos dispositivos constitucionais, pode dar ao caso uma solução que, não necessariamente, obedece ao princípio democrático, visto por um viés apenas de democracia formal. Por outro lado, por meio de soluções, muitas vezes, contramajoritárias, o Judiciário permite a efetivação de direitos fundamentais de minorias excluídas das tomadas de decisão políticas.

Ocorre que com o aumento da atuação do Poder Judiciário, em especial do STF, tem se tornado ainda mais patente a necessidade de se analisar os "limites" democráticos da atuação do Judiciário em geral e do Supremo em particular. Essa análise deve ser feita ao lado do imperativo constitucional de eficácia imediata dos direitos fundamentais (art. $5^{\circ}, \S 1^{\circ} \mathrm{da} \mathrm{CF} / 88$ ).

Ultrapassada a questão de quem e como efetivar os direitos fundamentais, a análise será feita sob a ótica da justiça. Uma norma constitucional que não gera efeitos pode causar injustiça? E se tratar-se de normas de direitos fundamentais? O conceito de justiça é também um problema a ser resolvido, uma norma que é efetiva é sempre justa? Para tanto, será utilizado o conceito de justiça de John Rawls, problematizando-o frente à algumas hipóteses de inefetividade de normas constitucionais a fim de analisar, com base nos seus princípios de direito, se tal inefetividade é vetor de injustiça.

É importante salientar que o trabalho cuida da efetividade das normas constitucionais, o que deve ser compreendido como uma eficácia social, ou capacidade de gerar efeitos práticos na vida dos indivíduos.

Por fim, esclarece-se que o presente trabalho, com a pretensão de ser científico, lançará mão do método de abordagem hipotético-dedutivo, partindo sempre de uma análise doutrinária e jurisprudencial consolidada.

\section{EFETIVIDADE DAS NORMAS CONSTITUCIONAIS}

Um dos problemas sobre o qual a teoria do direito tem se debruçado 
com bastante vigor é a questão da efetividade dos direitos, em especial dos direitos prestacionais (BOTELHO, 2009, p. 557).

Neste sentido, vem a calhar a já bem conhecida lição de Norberto Bobbio (1992, p. 24): “o problema fundamental em relação aos direitos do homem, hoje, não é tanto o de justificá-los, mas o de protegê-los. Trata-se de um problema não filosófico, mas político"’.

Antes de adentrar no debate da efetividade das normas constitucionais, é necessário delinear em que contexto será abordado o tema da efetividade. Quanto a isso, é importante dizer, com Barroso $(2009,84)$, que "o direito existe para realizar-se" e, sob essa premissa, tentar-se-á construir um trabalho que faça uma análise da realizabilidade das normas constitucionais no Brasil, em especial após 1988.

A questão, então, que se coloca sob o pálio do debate da efetividade, é o de demonstrar que a Constituição brasileira, após 25 anos de vigência, ainda possui dispositivos que não geram efeitos práticos e tentar demonstrar os caminhos e entraves que a doutrina aponta na efetivação dos direitos fundamentais.

Alguns, dispositivos nem mesmo chegaram a gerar efeitos jurídicos e já foram retirados de vigência (art. 192, $\left.\S 3^{\circ}\right)^{3}$, outros, apenas conseguiram ganham um mínimo de aplicabilidade após a intervenção do Poder Judiciário (art. 37, VII $)^{4}$.

Para se fazer essa análise deve-se tomar por base o conceito de constituição normativa, tal qual em Hesse (1991, p.24), para quem a Constituição logra conferir forma e modificação à realidade. Ela logra despertar 'a força que reside na natureza das coisas', tornando-a ativa. Ela própria converte-se em força ativa que influi e determina a realidade política e social.

Nesse ponto, é importante salientar que a atribuição de força normativa à Constituição é algo que se aloca dentro de um contexto contemporâneo de Constituição, tal como se concebe a lei maior brasileira de 1988 e o Direito Constitucional brasileiro (CANOTILHO, 2001, p. VI), o que coloca a Constituição em uma posição de hierarquia e centralidade dentro sistema jurídico em relação as demais normas jurídicas, bem como assegura normatividade das suas normas (BARCELLOS, 2007, p. 3)

Ademais, para além de uma retórica de normatividade constitucional,

\footnotetext{
${ }^{2}$ É importante ressaltar que mesmo estando consolidada a justificação dos direitos fundamentais e humanos (não é objeto do trabalho essa distinção), é possível ver na doutrina algum debate acerca da justificação dos direitos humanos, em especial em relação ao universalismo de tais direitos. Sobre o tema ver o artigo BENHABIB, Seyla. outrouniversalismo:sobrelauniversidad y diversidade de losderechos humanos. Isegoria revista de Filosofia mora y política, N. 39. Pgs 175-203, jul-dez, 2008. ${ }^{3}$ Revogado pela emenda Constitucional nº40/2003

${ }^{4}$ Direito de greve dos servidores públicos que ganhou novos contornos após o julgamento do MI 708/2007 - relator Ministro Gilmar Mendes.
} 
a própria Constituição brasileira de forma expressa assegurou eficácia imediata aos direitos fundamentais (art. $5^{\circ} \S 1^{\circ} \mathrm{da} \mathrm{CF} / 88$ ).

Quanto aos direto fundamentais, esses devem ser concebidos como um consenso mínimo indispensável, além de se conformarem dentro de um contexto material de constituição contemporânea, ou seja, se a constituição possui a centralidade do ordenamento jurídico, os direitos fundamentais e a dignidade humana possuem a centralidade substancial da Constituição (BARCELLOS, 2007, p. 4).

Para que não haja confusões terminológicas é necessário distinguir, desde já, o sentido em que serão compreendidos termos como efetividade, eficácia e aplicabilidade dos direitos fundamentais.

A doutrina, em especial autores como Ingo Wolfgang Sarlet, Luis Roberto Barroso, José Afonso da Silva, estabelece uma diferenciação entre eficácia jurídica, ligada ao tema da aplicabilidade, e eficácia social, voltada para análise da efetividade das normas constitucionais.

Desta forma, eficácia é o gênero, efetividade e aplicabilidade são espécies. Este trabalho preocupa-se mais com a questão da efetividade.

Antes, contudo, de tratar do tema da efetividade é preciso ter compreensão do que significa, para a doutrina, o termo eficácia. Para José Afonso da Silva (2002):

Uma norma só é aplicável na medida em que é eficaz. Por conseguinte, eficácia e aplicabilidade das normas constitucionais constituem fenômenos conexos, aspectos talvez do mesmo fenômeno, encarados por prismas diferentes: aquela como potencialidade; esta como realizabilidade, praticidade.

Para Luis Roberto Barroso (2009, p. 81), “a eficácia dos atos jurídicos consiste na sua aptidão para a produção de efeitos, para a irradiação de consequências que lhe são próprias".

Ainda, para José Afonso da Silva (2002, p. 56) “a eficácia diz respeito à aplicabilidade, exigibilidade ou executoriedade da norma". Contudo, a análise da eficácia e da operatividade dos direitos fundamentais terá caminhos diferentes se o objetivo for estudar a aplicabilidade ou a efetividade dos direitos fundamentais, repita-se tomando-se ambos como espécies do gênero eficácia (SARLET, 2010, p. 235).

A eficácia jurídica deve ser concebida como a capacidade de um dispositivo constitucional gerar efeitos jurídicos, tais como o de revogar uma lei infraconstitucional, ou seja, para a eficácia jurídica será importante saber se o dispositivo constitucional é capaz de gerar todos os efeitos ou se lhe carece alguma complementação.

Ainda, quanto a questão da aplicabilidade das normas constitucionais, Barroso (20009, p. 82), citando a lição de José Afonso da Silva e de Ruy Barbo- 
sa, assinala "que não há, em uma Constituição, cláusula a que se deva atribuir meramente o valor moral de conselhos, avisos ou lições".

Para José Afonso da Silva (p. 3 e 68) todos os dispositivos constitucionais "têm força imperativa de regras, ditadas pela soberania nacional ou popular aos seus órgãos", o que faz presumir que nenhum dispositivo constitucional, independentemente da forma como foi positivado é destituído de alguma força normativa, mesmo que ainda careça de uma integração legislativa ou de política pública.

Por sua vez, a eficácia social difere da eficácia jurídica. Entretanto, em muitos casos a condição de efetividade da norma estará ligada a aspectos inerentes à aplicabilidade do texto normativo, é o caso do art. $192, \S 3^{\circ}$ da Constituição Federal, cuja inaplicabilidade impediu que gerasse qualquer tipo de efeitos ${ }^{5}$.

Em relação a efetividade, nas palavras de Reale (1973, p.135), pode ser concebida como, "o reconhecimento (anerkennung) do Direito pela comunidade ou, mais particularizadamente, aos efeitos que uma regra suscita através do seu cumprimento".

Para Barroso (2009, p. 82) eficácia social será a "concretização do comando normativo, sua força operativa no mundo dos fatos". Ainda para o constitucionalista carioca, efetividade significa a realização do Direito, o desempenho concreto de sua função social. Ela representa a materialização, no mundo dos fatos, dos preceitos legais e simboliza a aproximação, tão intima quanto possível, entre o dever-ser normativo e o ser da realidade social (BARROSO, 2009, p. 82)

Barroso (2009, p. 83) ainda identifica alguns fatores que podem proporcionar inefetividade de um dispositivo normativo. Para o referido autor, questões como um texto que estabelece uma conduta contrária a um sentimento social arraigado, uma regra que contrarie interesses de pessoas com poderes para manipular a aplicação da norma ou ainda quando o conteúdo da regra estabelecer uma conduta irrealizável ou plenamente absurda são hipóteses capazes de gerar inefetividade do dispositivo constitucional.

Desta forma, é possível delinear qual o sentido do termo efetividade e qual o alcance do problema que se coloca em debate, mas esta é apenas uma parte do problema.

Autores como Luis Roberto Barroso, resolvem o problema da (in)efetividade dos dispositivos constitucionais com a identificação de ferramentas previstas no ordenamento jurídico capazes de vindicar a efetivação de direitos

${ }^{5}$ É de salientar que no caso da ADI 4-7 DF, o STF entendeu que o art. $192, \S 3^{\circ}$ da CF dependia de lei complementar para que o dispositivo constitucional gerasse efeitos jurídicos. Veja-se que neste caso, a ausência de eficácia da norma (porque produto de interpretação) decorreu especificamente de interpretação do STF, que mesmo tendo a possibilidade de dar ao menos uma eficácia mínima à norma, optou por destituí-la de qualquer eficácia social ou jurídica. 
fundamentais. No caso brasileiro, ações como o mandado de Injunção e a ADO (Ação direito de inconstitucionalidade por omissão) e a ação popular cumprem esse papel.

Entretanto, a própria efetivação da Constituição por meio do Poder Judiciário é ponto que merece ser discutido à parte, visto que a ausência de efetividade de um dispositivo constitucional pode estar vinculada a uma atuação específica do Poder Legislativo ou do Executivo, sendo o ponto nevrálgico da questão exatamente o de saber se o Poder Judiciário pode, legitima e validamente, atuar nessas searas.

\section{EFETIVIDADE CONSTITUCIONAL: PROCEDIMENTALISMO E SUBSTANCIALISMO}

A questão da inefetividade dos direitos fundamentais está, nas palavras de Reis (in GARCIA, 2004, p.357) situada nas "omissões legislativas" e na questão da aplicação de políticas públicas voltas para a efetivação de direitos fundamentais.

Assim, o problema da ausência de efetividade de alguns direitos fundamentais estaria sediada na omissão dos membros do Poder Legislativo e na má, ou omissa, atuação dos membros do Poder Executivo. Ademais, como é sabido "a promoção e proteção dos direitos fundamentais exigem omissões e ações estatais" (BARCELLOS, p. 10), sobremaneira do Executivo e o Legislativo.

Desta forma, a inefetividade de um dispositivo constitucional que estabelece direitos fundamentais, seja pela ausência de uma política pública de qualidade, seja pela ausência de norma regulamentadora, via de regra acaba no seio do Poder Judiciário, em especial em países como o Brasil em que há um "deslocamento da esfera de tensão, até então calcada nos procedimentos políticos, para os procedimentos judiciais" (STRECK, 2009, p. 38).

É importante ressaltar que muitas vezes a escolha feita pelos Poderes Executivo e Legislativo advém de uma escolha democrática, no sentido adjetivo ou procedimentalista, ou seja, é o resultado da escolha da maioria ou, no mínimo, vem legitimado pelo voto proferido nas eleições.

Neste viés, é possível pensar, talvez, em uma escolha feita democraticamente que proíba casamento entre pessoas do mesmo sexo. Contudo, como bem lembra Fernando de Brito Alves (2013, p.51), "é preciso considerar que as teorias da democracia têm uma responsabilidade muito maior do que problematizar modelos de participação; elas devem discutir princípios de justiça substantiva".

Assim, o problema que se coloca é de saber se o Poder Judiciário pode substituir os Poderes Executivo e Legislativo com o fim de dar às normas constitucionais um mínimo de efetividade, mesmo que democraticamente essa escolha 
tenha sido feita em sentido aparentemente "injusto" ou em casos em que a "injustiça" decorra da omissão inconstitucional.

Essa questão passa pelo embate acerca da postura mais procedimentalista ou substancialista do intérprete constitucional da qual adiante se irá tratar. Ressalte-se que mesmo que esta polarização entre procedimentalismo e substancialismo não esteja completamente atrelada à questão da efetividade das normas constitucionais, é possível fazer uma análise sob esse enfoque.

Sobre procedimentalismo e substancialismo, cita-se a lição de Ana Paula de Barcellos:

A primeira delas sustenta que cabe à constituição impor ao cenário político um conjunto de decisões valorativas que consideram essenciais e consensuais. Essa primeira concepção pode ser descrita, por simplicidade, como 'substancialista'. Um grupo importante de autores, no entanto, sustenta que apenas cabe à Constituição garantir o funcionamento adequado do sistema democrático, ficando a cargo da maioria, em cada momento histórico, a definição de seus valores e de suas opções políticas. Nenhuma geração poderia impor à seguinte suas próprias convicções materiais. Esta segunda forma de visualizar a Constituição pode ser designada de 'procedimentalismo' (BARCELLAR, 2007, p. 7)

Assim, a questão de fazer ou não uma lei que permita dar efetividade aos direitos fundamentais ou a implementação de políticas públicas ou destinação de gastos públicos está dentro da seara de autonomia dos Poderes Executivo e Legislativo. Se é assim, qual é o limite do Poder Judiciário quando se depara com a ofensa a direitos fundamentais advindos da má ou ausente atuação dos demais poderes em tais procedimentos?

Quanto ao problema da omissão legislativa, o próprio ordenamento prevê algumas "soluções", haja vista a existência do mandado de Injunção e da Ação direta de Inconstitucionalidade por omissão.

A questão referente a eficácia de tais ações reclama, talvez, um trabalho próprio, visto que em tais casos, quem dará a última palavra será o Poder Judiciário, contudo, sem se cogitar que atue no lugar do Legislador, ou seja, uma guinada de 360 graus ${ }^{6}$.

Em relação ao Executivo, algumas questões mais pontuais são apresentadas: limitações financeiras -escassez de recursos- e a discricionariedade administrativa em relação à escolhas de políticas públicas são os argumentos mais utilizados de maior robustez.

Note-se que nesse cenário, quase sempre a "solução" desemboca no Poder Judiciário, ou seja, se o Legislador não faz a lei, ajuíza-se uma ação para que o Judiciário diga que não fez e, além disso, tome uma providência, se o Executivo não implementa uma política pública prevista constitucionalmente, ajuíza-se

${ }^{6}$ Ver o mandado de Injunção nº 708/2007 - relator Ministro Gilmar Mendes. 
uma ação para que o Judiciário decida sobre tais questões.

A opção apresentada por autores como Celso Antonio Bandeira de Melo, Ana Paula de Barcellos, entre outros, parte de uma ideia substancialista de constituição.

Para o primeiro, não há esfera de discricionariedade, mas sim uma vinculação em maior ou menor grau, visto que todos os atos do Poder executivo devem estar sempre voltados para a efetividade máxima das normas constitucionais.

Vale dizer, o administrador Público e o Legislador estão sempre vinculados à Constituição e mesmo quando a Constituição estabelece faculdade de criação de leis ou um programa constitucional; estes dispositivos devem ser obedecidos com base na busca pela efetividade máxima ou ótima das normas constitucionais.

Para Ana Paula de Barcellos, é possível estabelecer um programa de efetivação de direitos fundamentais sem estar obstado pela reserva do financeiramente possível. No entender da professora carioca, existem metas constitucionais que são prioritárias e é dever do administrador público e do legislador atendê-las com prioridade a qualquer outra meta do Estado.

\section{A EFETIVIDADE É TAMBÉM UM PROBLEMA DE (IN)JUSTIÇA?}

A questão que aqui se coloca, tendo por base a ideia de efetividade acima estabelecida, é de saber se pode-se afirmar que a inefetividade de determinados dispositivos constitucionais que estabelecem direitos fundamentais é uma questão que pode ser analisada sob o pálio das teorias da justiça, seja ela em abstrato, seja ela em um caso específico, em outras palavras, a inefetividade das normas constitucionais, podem ser consideradas como vetores de injustiça? Para tanto, tomar-se-á por base a teoria da Justiça de John Rawls.

\section{A TEORIA DA JUSTIÇA DE JOHN RAWLS}

Rawls parte da ideia de uma justiça igualitária -igualitarismo liberalbem aos moldes de uma Constituição como a brasileira, que tem na justiça social a pilastra que sustenta a ordem econômica.

Além disso, essa concepção de justiça proposta por Rawls estabelece de forma mais harmônica a relação entre liberdade e igualdade do que outras propostas de justiça, assim como faz a Constituição brasileira (art. $5^{\circ} \mathrm{da} \mathrm{CF} / 88$ ) que, por ser eclética, harmoniza interesses liberais e sociais.

Vale dizer, a igualdade é marco essencial na teoria de justiça de Rawls, assim como é no sistema constitucional brasileiro. Entretanto, o fato de consi- 
derar a igualdade como a primeira causa na qual deva se aplicar os princípios de justiça, não conduz a teoria de Rawls a uma justiça distributiva, em que pese, no Brasil, ser esta uma política vigente. Contudo, isso não obsta que se tente analisar os problemas sociais decorrentes da inefetividade das normas constitucionais a partir de um ideal de justiça como equidade, que foi desenvolvido por John Rawls (2000, p.4).

John Rawls é contratualista (GARGARELLA, 1999, p. 30), mas não nos mesmos termos que Hobbes, Locke e Rousseau, pois Rawls parte de uma ideia de condição ideal de acordo, mais do que isso, parte de uma ideia de que "ninguna persona se encuentra inerentemente subordinada frente alasdemás." (GARGARELLA, 1999, p. 33)

Desta forma, a escolha pela teoria da justiça de Rawls se dá, dentre outras, pelo fato de que está pautada em uma ideia forte de igualdade moral desde a formação do pacto inicial. Rawls parte de uma ideia de igualdade moral entre os indivíduos para estabelecer o pacto inicial da sociedade; essa igualdade não é apenas física, como em Hobbes, mas moral, pelo simples fato de todos os contratantes serem humanos. (GARGARELLA, 1999, p. 34 e 35).

A questão que se coloca em Rawls, então, passa pela escolha dos princípios de justiça escolhidos na posição original, escolhidos, diga-se de passagem, em condição de igualdade, que se estabelece, dentre outros, pelo véu da ignorância.

Os princípios de justiça de que trata John Rawls são os seguintes (2000,

Primeiro: cada pessoa deve ter um direito igual ao mais abrangente sistema de liberdades básicas iguais que seja compatível com um sistema semelhante de liberdades para as outras.

Segundo: as desigualdades sociais e econômicas devem ser ordenadas de tal modo que sejam ao mesmo tempo (a) considerada para vantajosas para todos dentro dos limites do razoável, e (b) vinculadas a posições e cargos acessíveis a todos.

Desta forma, com base nesses princípios escolhidos por todos os contratantes que estavam em condições de igualdade na posição original, é que deve ser medido o grau de justeza de uma sociedade. Para Rawls, "a justiça é a primeira virtude das instituições sociais" e esses princípios, segundo o autor, podem dar parâmetros para analisar se as instituições sociais são realmente justas.

Ainda, para Rawls (2000, p. 7 e 8),

O objeto primário da justiça é a estrutura básica da sociedade, ou mais exatamente, a maneira pela qual as instituições sociais mais importantes distribuem direitos e deveres fundamentais e determinam a divisão de vantagens provenientes da cooperação social. Por instituições mais importantes quero dizer 
a constituição política e os principais acordos economicos e sociais.

Assim, para o autor em análise, os institutos jurídicos não devem ser apenas ordenados e eficientes, devem ser também justos (GARGARELLA, 1999, p. 21). Desta forma, aparentemente, justiça nada tem a ver com a efetividade, podendo ser uma norma efetiva e injusta ou infetiva e, mesmo assim, não gerar qualquer tipo de injustiça ou até mesmo ser justa.

Se assim o é, pode-se retornar a ideia de que uma norma é inefetiva quando não alcança, na prática, aquilo que em tese estabeleceu, ou ainda, por outro lado, "uma constituição é eficaz se as normas postas de conformidade com ela são, globalmente e em regra, aplicadas e observadas" (KELSN, 2006, p. 234).

Diante disso, pode-se tomar por base determinadas normas constitucionais que não são efetivamente aplicadas, seja pela ausência de uma norma integradora, seja pela ausência de políticas públicas que lhe deem efetividade.

Note-se que tanto em um quanto noutro caso, o problema resulta da ausência de cumprimento da função típica dos órgãos Legislativo e/ou Executivo. É possível também uma inefetividade que decorra da interpretação que se dá a determinado texto jurídico, pecha que pode recair sobre qualquer dos poderes estatais.

Diante disso, pode-se tomar para o caso, mas por razões diferentes, a pergunta feita por Rawls, especificamente para saber se ao não agir como determina a Constituição, os órgãos Estatais funcionam de modo justo? (GARGARELLA, 1999, p. 21)

\section{A REALIDADE BRASILEIRA SOB A ÓTICA DA JUSTIÇA}

É importante ver de que tipo de inefetividade se está tratando. Em relação a realidade brasileira, citam-se alguns exemplos aleatórios.

Primeiramente, $\mathrm{o}$ art. $5^{\circ}$ XLIV estabelece que "é assegurado aos presos o respeito à integridade física e moral" e deve ser conjugado com o art. $5^{\circ} \mathrm{III}$ "ninguém será submetido a tortura nem a tratamento desumano ou degradante". Contudo, há hoje uma superlotação do sistema prisional brasileiro em todas as regiões do país de cerca de $71 \%$, segundo dados do Centro Internacional de Estudos Carcerários (ICPS), ou seja, há próximo de 229 mil presos no sistema carcerário acima daquilo que o sistema carcerário está capacitado a receber.

Ainda, segundo medida 10 do Plano nacional de política Penitenciária (DEPEN/MJ),

Constatam-se celas sem nenhuma ventilação, iluminação ou incidência de sol e com pé direito baixo em localidades com médias de temperatura de 30 a 40 graus Celsius. Ou unidades que só tem celas, sem espaço para visitas, atividades educativas ou laborais, administrativas ou alojamento para funcionários. 
Desta forma, parece distante do dispositivo Constitucional que prevê cumprimento de pena em ambiente que respeite a integridade física e moral do preso, sendo degradante e desumano.

Ainda, o art. $6^{\circ}$ estabelece que é direito fundamental social o direito a saúde. Dentro do conceito de direito a saúde está o direito ao saneamento básico que, por sua vez, é composto por água potável, ligação de rede de esgoto e tratamento deste esgoto.

O art. 200, IV da CF/88, estabelece como competência do SUS "participar da formulação da política e da execução das ações de saneamento básico". Contudo, o Brasil tem apenas 53,5\% das residências urbanas com coleta de esgoto e, deste esgoto gerado, apenas $37,9 \%$ recebem tratamento, sendo ainda que apenas cerca de $92,5 \%$ da população tem acesso à água potável. (SNIS 2011)

É possível ainda citar, como exemplos de inefetividade das normas constitucionais que asseguram direitos fundamentais o art. $7^{\circ}$, IV da CF/88 (salário mínimo) que segundo dados do DIEESE deveria ser ao menos 4 vezes maior para alcançar aquilo que está previsto constitucionalmente (DIEESE). O já citado art. $192, \S 3^{\circ}$ da $\mathrm{CF} / 88$ que foi revogado sem poder gerar efeitos (súmula vinculante $\mathrm{n}^{\circ} 7$ do STF) e o art. 37, VII da Constituição Federal, podendo-se falar ainda do direito à saúde (em especial quando se trata de mistanásia) ou ainda do acesso à educação e do grande contingente de pessoas analfabetas (cerca de 13 milhões de pessoas segundo dados do PNAD/2012).

Aparentemente, as escolhas de políticas públicas, além de outras razões que merecem um estudo próprio, são tomadas com base em um conceito de justiça baseado no intuicionismo que muda a cada governo, ou quando há uma troca significativa nos governos, do ponto de vista político partidário.

Sendo assim, não é difícil também encontrar resquícios de uma política pública ou uma escolha legislativa pautados em um conceito de justiça utilitarista, em especial quando se fala do caso dos presídios. A maioria da população está fora dos presídios -uma média de 247 presos a cada cem mil habitantes- (ICPS), ou seja, parece que se pode considerar acertado para essa grande maioria que está fora das penitenciárias, que aqueles que cometem crimes sejam enviados para os presídios, mesmo que para cumprir a pena em condições completamente desumanas.

Em alguns casos, no Brasil, nem mesmo se pode dizer que a ausência de efetividade de direitos fundamentais se deve à aplicação de uma lógica utilitarista, visto que é a maioria que não tem acesso à determinados direitos fundamentais, p.e como o caso do tratamento de esgoto (apenas 37,9\% das residências no Brasil têm esgoto tratado).

É importante ressaltar que quando se fala em direitos fundamentais, a quantidade "não importa", pois a ausência de acesso à determinado direito 
fundamental ofende diretamente a esfera jurídica do ser humano, que não pode ser contado como um percentual na pesquisa, mas como um valor em si mesmo, enquanto ser humano.

Aqueles que ainda não têm acesso a direitos fundamentais devem ser considerados como pessoas que ainda não puderam sentir os efeitos reais à previsão constitucional de direitos fundamentais em suas vidas.

Nesse sentido, é possível questionar-se, por exemplo, com base em que tipo de justiça (social) são feitas as escolhas políticas para a implementação ou não de políticas públicas que deem efetividade a direitos fundamentais; não que não as tenha, pois em grande parte tem, mas as políticas públicas existentes são em uma proporção que ainda permite que parcela muito grande da sociedade não sinta qualquer efeito prático da previsão constitucional que estabelece direitos fundamentais.

\section{A INEFETIVIDADE DAS NORMAS DE DIREITOS FUNDAMENTAIS E A TEORIA DA JUSTIÇA DE JOHN RAWLS}

Como dito acima, para Rawls, os princípios de justiça estão ligados à liberdade básica para todas as pessoas e a uma desigualdade que seja justa ou vantajosa para todos.

No caso brasileiro, o primeiro princípio já sofre algumas restrições, a saber, a ausência de efetividade de algumas normas constitucionais não asseguram liberdade básica para todos. Veja-se o caso dos Estados do Paraná7 e de Santa Catarina que mesmo depois de 25 anos de vigência da atual Constituição ainda não implementaram um sistema de defensoria pública. Com isso, aqueles que são financeiramente debilitados, ficam, em tese, sem acesso efetivo ao judiciário por meio de uma prestação estatal.

Vale ressaltar, em relação ao princípio de justiça, quanto ao acesso igual às liberdades básicas, os dados trazidos pelo DEPEN/MJ na medida 6:

No sistema prisional brasileiro $44 \%$ dos presos são provisórios. Porém, o CNJ identificou que os índices de presos provisórios são diferentes nas unidades da Federação, sendo que o Distrito Federal possui o menor percentual, 20\%, e o Piauí, o maior, 74\%. De qualquer forma, segundo dados da International Bar Association2, uma em cada cinco destas prisões é ilegal. Este fenômeno se deve à banalização da prisão cautelar, hoje concedida rotineiramente pelos juízes de primeira instância, que muitas vezes apenas homologam as prisões em flagrante realizadas pela polícia, sem que haja fundamentação apropriada. Se analisarmos o comportamento do Poder Judiciário, veremos que em incontáveis vezes o uso da prisão provisória é feito em desacordo com a Constituição Federal. Isto pode

${ }^{7}$ A Implantação da defensoria pública no Estado Paraná teve início no ano de 2013 apenas.

Rev. Ciênc. Juríd. Soc. UNIPAR, v. 17, n. 2, p. 243-259, jul./dez. 2014 
ser verificado nos mutirões carcerários do $\mathrm{CNJ}$, que revisaram 156.708 processos e beneficiaram 41.404 presos, dos quais 23.915 foram postos em liberdade.

Ainda, em relação à implantação das Defensorias Públicas, enquanto meio de proporcionar liberdades básicas a todos os indivíduos, cita-se uma vez mais, dados oficiais do DEPEN/MJ trazidos na medida 7

Ainda há três Estados no País que não possuem Defensoria Pública instalada, e quase $50 \%$ dos demais Estados têm quadros de pessoal muito aquém do necessário. A maioria dos presos brasileiros é pobre, e sem a Defensoria Pública plenamente instalada não tem direito à defesa ou ao acompanhamento na fase da execução penal. As consequências são inúmeras.

Veja-se que neste caso, a desigualação também não é justa e vantajosa para ninguém.

Em relação a ausência de ato normativo integrador de dispositivo constitucional, para lançar mão de outro exemplo, cita-se a ainda não elaborada lei de greve do servidor público (Art. 37,VII da CF/88). Veja-se que se trata de direito fundamental do trabalhador -direito de greve-, mas o tratamento diferenciado entre servidores públicos e empregados da iniciativa privada estabelece uma desigualdade injusta, pois os funcionários da iniciativa privada podem fazer greve e os funcionários públicos não, e não o podem especificamente por conta da ausência de norma integradora.

Essa não é uma desigualdade que seja proveitosa para todos, visto que uma parte significativa da população é composta de servidores públicos que, por ausência de atuação do Poder Legislativo em dar aplicabilidade ao direito de greve dos servidores públicos, os deixa manietados do exercício deste direito fundamental ${ }^{8}$.

Outra questão que interessa bastante está ligada desigualdade social. Além da equalização ser uma política de estado estabelecida nos objetivos fundamentais da República (Art. $3^{\circ}$, III) depende de uma articulação que envolve os órgãos legislativo, Executivo e Judiciário.

O Brasil, segundo reportagem publicada no Estado de São Paulo de 24 de julho de 2010, é o terceiro pior país do mundo em desigualdade. Dentre outros aspectos ressalta-se a desigualdade de renda. Entretanto, a constituição estabelece, desde 1988 a possibilidade de implantação de tributos sobre grandes fortunas, que exige a elaboração legislativa (art. 153, VII), mas passados cerca de 25 anos da promulgação da Constituição ainda não foi implantado o referido tributo.

Sendo assim, quando procurado, a resolver tais problemas, seja em que esfera de Poder for, o estado precisa analisar a inefetividade das normas consti-

${ }^{8}$ Como já salientado, o STF apresentou uma solução alternativa para o caso, tirando da própria constituição uma interpretação que permita dar ao texto constitucional uma eficácia mínima. Ver MI 708/2007 - relator MinistroGilmar Mendes. 
tucionais também como um fator de justiça e não apenas de eficácia ou não das referidas normas.

Talvez o critério adotado não resolva, definitivamente, problemas como a questão das limitações financeiras, mas pode dar um argumento forte para justificar a atuação do Estado, seja por qual dos seus órgãos for, mas, neste caso, preocupada com tornar efetivos os direitos fundamentais, posto que por este ponto de vista, as escolhas políticas na implementação de políticas públicas não são apenas uma questão de oportunidade ou de agenda política, mas de justiça, sendo que a justiça, neste caso, tem critérios objetivos para ser apurada.

\section{CONSIDERAÇÕES FINAIS}

O problema de atribuir eficácia às normas constitucionais está no centro dos debates da contemporaneidade, em especial pela necessidade de países como o Brasil têm de implantar um regime político duradouro e legítimo. Além disso, a própria concepção de constituição, concebida como texto normativo com capacidade jurídica de gerar efeitos, reclama que suas normas sejam efetivamente aplicadas.

Entretanto, as dinâmicas sociais e políticas nem sempre se adequam aos preceitos constitucionais, as variáveis vêm sobre vários argumentos, mas têm na sua raiz o problema de uma ausência de consciência constitucional. No Brasil, em que pese ter uma tradição constitucional desde o século retrasado, apenas agora se experimenta a sensação de se ter uma constituição que rege a sociedade e não uma que apenas legitima o status quo do governante.

Assim, se não há ainda na consciência política uma verdadeira vontade constitucional, mas ao mesmo tempo não há uma crise que a empurre para o desuso, é necessário que se implemente fortemente as suas normas, em especial aquelas garantidoras dos direitos fundamentais.

A questão é, a constituição estabelece apenas os procedimentos para a sua implementação ou é ela própria a fonte donde se pode tirar as soluções, vale dizer, a constituição se impõe por si só ou é ponte para o exercício do jogo democrático?

Uma dúvida não há. A constituição nasceu para ser vetor de mudança social, nasceu para constituir o Estado brasileiro e, por isso, merece ter seus dispositivos efetivamente implementados, mas por quem?

Pelo Estado que a própria Constituição inaugurou em 1988, por todos os seus órgãos. Mas qual deve ser o órgão a dar a última palavra em matéria de implementação de direitos fundamentais? Esse tema ainda precisa ser melhor desenvolvido.

A ausência deimplementação de direitos fundamentais, pelo conceito 
de Justiça de John Rawls gera injustiça. Em que pese isso parece óbvio, poderia não ser assim, se o critério de justiça utilizado fosse outro, como o da justiça utilitarista.

A teoria de Rawls colabora com princípios que permitem aferir, como um todo, a justiça da ação ou omissão do Estado em matéria de direitos fundamentais. Em que pese a teoria da Justiça de Rawls não ter o condão de ser analisada em casos específicos, mas para analisar o ordenamento jurídico como um todo, é possível, diante da análise da inefetividade de determinados direitos fundamentais, chegar-se à conclusão que se diante de uma injustiça.

Por fim, parece ser possível dizer que ao tratar de temas como o da eficácia de direitos fundamentais, o Poder Judiciário, ou qualquer outro Órgão, pode deslocar o debate do campo meramente econômico e político, para o campo da justiça, da teoria do direito, ganhando como argumento a injustiça da não implementação de direitos fundamentais em troca de outros direitos não tão fundamentais assim.

\section{REFERÊNCIAS}

ALVES, F. de B. Constituição e participação popular: A construção histórico-discursiva do conteúdo juridico-político da democracia como direito fundamental. Curitiba: Juruá, 2013.

BARCELLOS, A. P. de. Neoconstitucionalismo, direitos fundamentais e controle das políticas públicas. Revista Diálogos Jurídicos, Salvador-BA, n. 15, p. 1-31, jan./ mar. 2007.

BARROSO, L. R. O Direito constitucional e a efetividade de suas normas limites e possibilidades da Constituição brasileira. 9. ed. Rio de Janeiro: Renovar, 2009.

BOBBIO, N. A era dos direitos. Rio de Janeiro: Elsevier, 2004.

BOTELHO, M. C. Procedimentalismo em Alexy e papel da corte constitucional. Argumenta revista jurídica, Jacarezinho, v. n. 10, p. 37-52, 2009.

. O fornecimento de medicamentos pelo Estado: Considerações à luz do pensamento de Klauss Günther. BDA-Boletim de Direito Administrativo, p. 557-566, maio 2009. 
BRASIL. Constituição (1988). Constituição da República Federativa do Brasil: promulgada em 5 de outubro de 1988. Brasília: Senado Federal, 2005. $435 \mathrm{p}$.

CENTRO Internacional de Estudos Carcerários (ICPS). <http://www. prisonstudies.org/info/worldbrief/wpb_country.php? country=214>. Acesso em: 31 set. 2013.

CANOTILHO, J. J. G. Constituição dirigente e vinculação do legislador. 2. ed. Coimbra: Coimbra, 2001.

DEPEN/MJ. Disponível em: <http://portal.mj.gov.br/main. asp? View $=\{$ E9614C8C-C25C-4BF3-A238-98576348F0B6 $\} \&$ BrowserType $=$ NN\&LangID=pt-br\&params=itemID\%3D \%7BD1903654-F845-4D59-82E839C80838708F\%7D\%3B\&UIPartUID=\%7B2868BA3C-1C72-4347-BE11A26F70F4CB26\%7D>. Acesso em: 28 set. 2013.

GARGARELLA, R. Las teorias de la justicia despues de rawls um breve manual de filosofia política. Barcelona: Paidós, 1999.

HESSE, K. A força normativa da Constituição. Porto Alegre: S. A. F. 1991.

KELSEN, H. Teoria pura do direito. São Paulo: M. Fontes, 2006.

RAWLS, J. Uma teoria da justiça. São Paulo: M. Fontes, 2000.

REIS. C. B. A. Notas acerca da Efetividade dos direitos fundamentais sociais como limite à discricionariedade Administrativa. In: GARCIA, Emerson. A efetividade dos direitos sociais. Rio de Janeiro: Lumen Iuris, 2004.

SARLET, I. W. Eficácia dos direitos fundamentais. 10. ed. Porto Alegre: Livraria do Advogado, 2010.

SILVA, J. A. da. Aplicabilidade das normas constitucionais. 6. ed. São Paulo: Malheiros, 2002.

STRECK, L. L. Hermenêutica jurídica e(m) crise uma exploração hermenêutica da Construção do direito. 8. ed. Porto Alegre: Livraria do advogado, 2009. 


\title{
IS CONSTITUTIONAL INEFFECTIVENESS A PROBLEM OF (IN) JUSTICE?
}

\begin{abstract}
The Brazilian constitution is characterized by several fundamental rights it safeguards. These rights have, in thesis, a minimum social and legal effectiveness, as well as being immediate applicable. However, many of these fundamental rights do not generate any effect on people's lives. The lack of effectiveness, in many cases, is linked to the (non) role of the government agencies. The question sometimes ends in the Judicial Branch. Can the Judicial Branch, based directly on the Constitution, make the choices that the other Powers should make? If it does not do it, does it comply with the Constitution, which requires immediate applicability of the Fundamental Rights? Furthermore, based on the concept of justice by John Rawls, can one say that the ineffectiveness of fundamental rights is a vector of injustice? This essay aims to discuss these issues in the light of a normative constitution in a democratic state of law that is influenced by the waves of judicialization of conflicts.
\end{abstract}

KEYWORDS: Fundamental Rights; Justice; Substantialism; Proceduralism.

\section{¿INEFECTIVIDAD CONSTITUCIONAL ES UN PROBLEMA DE (IN) JUSTICIA?}

RESUMEN: La constitución brasileña es caracterizada por diversos derechos fundamentales. Esos derechos son dotados, en tesis, de un mínimo de eficacia social y jurídica, así como de aplicabilidad inmediata. Sin embargo, muchos de esos derechos fundamentales no generan cualquier efecto en la vida de las personas. La falta de efectividad, en muchos casos, está unida a la (no) actuación de los órganos del Estado. La cuestión, por veces, termina en el Judiciario. ¿Puede el Judiciario, con base directamente en la Constitución Federal hacer las elecciones que caben a otros poderes? Si no hace, ¿atiende la Constitución, que exige aplicabilidad inmediata a los Derechos Fundamentales? Además, con base en el concepto de justicia de John Rawls, ¿es posible decir que la inefectividad de los derechos fundamentales es vector de injusticia? El ensayo que se propone busca discutir tales cuestiones bajo la luz de una Constitución Normativa en un Estado Democrático de Derecho que está influenciado por las ondas de judicialización de los conflictos.

PALABRAS CLAVE: Derechos Fundamentales; Justicia; Substancialismo; Procedimentalismo. 